\title{
The Integration Between Chinese Characters Design and National Culture
}

\author{
Mengmeng Zhou \\ Art College, Yantai Nanshan University \\ Yantai, China \\ e-mail: 61910184@qq.com
}

\author{
Jiao Meng \\ Yang Zhai Middle School \\ Zibo, China \\ e-mail:275533144@qq.com
}

\begin{abstract}
Nowadays, there has been a wild gap between Chinese character' design and the design of Europe, America, Japan and Korea. The reason is that the designers ignore the Chinese culture while they are designing. Chinese characters are one part of great Chinese nation which has more than 5000year Chinese culture. How to combine the design of Chinese characters with Chinese culture becomes the important task of the development of national culture. This paper mainly focuses on the above problem.
\end{abstract}

Keywords-Chinese characters; character script; national culture; intergration; national characterristic

\section{INTRODUCTION}

With the development of Chinese politics and economic, the demand of the continuous development of the cultural and artistic activities is increasingly important. Only the material needs can't meet people's demand, they also pursue the spiritual ones. Especially in the construction of spiritual civilization, the relationship between the development of art field and the national culture [1] becomes closer and closer.

Chinese Character Font Design, a foundation course, which plays an important role in Art major. Not only must we think about the construction and development of the course Chinese Character Font Design, but also we should fully study the importance of the integration between the Chinese character font design and Chinese culture, and the exploration on how to combine the Chinese characters font design with the Chinese culture in such a big cultural background.

\section{THE EMERGENCE AND DEVELOPMENT OF CHINESE CHARACTERS}

Chinese characters are the record of Chinese words, which are one of the cultures of the Chinese nation. They are also the most widely used words in our country. They have a long history and different stages of development.

Since Chinese words appeared, they have experienced many stages such as the early hieroglyph stage, bones stage, words stage, prose stage, the seal character stage, official script stage, regular script stage, running script a stage and cursive script stage. After printing was invented, another various printing type faces appeared in order to meet the printing requirements.

\section{A. The seal character}

The seal character, including minor and seal script. Minor refers to oracle, jinwen, the Zhou dynasty, the six characters. They preserve the ancient hieroglyphs of obvious characteristics. Also known as' Qin Zhuan ', is the language of Qin. Simplified characters are minor. Features are well made neat form; the font is the Zhou dynasty easy to write. In the history of Chinese characters, it is a minor nationality, the transition between the official script and regular script.

\section{B. Official script}

Official script, which is also called han nationalities. One of the Chinese characters in common grave fonts. Writing effect is slightly wide and flat. Horizontal drawing is long and straight short, a rectangular shape.

\section{Inscriptions on Bones}

The late Shang dynasty oracle text is written or carved on bones. Jinwen is carved or texted on the casting in bronze vessels. The seal character is divided into minor and seal script again, it is the important stage of hair style of Chinese characters. Official script of the emergence and development have a long time evolution process, sort is various, but it was a favorite and get long-term use of words Regular script, the stroke dignified has been in use today, was seen as a standard font and for the world. Running script, is between regular script and cursive script, brush a cursive style of freedom, the seal character eight zhangcao, following a variety of ancient change.

\section{The Printing}

After printing was invented, text gradually develops in the direction of being suitable for engraving in order to adapt to the needs of the printing. Subsequently, the Song type face appeared with the "square" characteristic. With the development of cultural undertakings, Long Song, Flat song, Imitation Song, dynasty style typeface and other variants has been derived on the basis of the song typeface. These new fonts' appearance greatly met the demand of the Block printing and Traditional Movable Type printing. After the introduction of the modern western printing, the bold, artistic fonts, and other new characters appeared under the influence of the western words. 
However, as the song typeface is suitable for the block printing and also it' s comfortable for people to read, it has been in use ever since and become the main character in publishing.

\section{Chinese Characters AND National CUlture}

Chinese language is the carrier of Chinese cultural information. National culture includes various types of culture. There are various kinds of relationships between the Chinese characters and the national Chinese national culture.

\section{A. National Culture Behavior}

The occurrence of the behavior of the national culture is mostly based on language. The development of the language has important influence on people's mind, social life, literature and art. For example, there are many Chinese dialects, which will provide the conditions for the formation, development and the enrichment of the regional art.

\section{B. The Perspective of Chinese Culture}

Macroscopically speaking, we can regard Chinese characters as one part of the culture, and then we can explore the relationship between other culture elements and it. Microcosmically speaking, the Chinese characters can be considered as the carrier of the culture, in this aspect, we can study the culture information that it conveys. [2] The cultural information that the characters convey is the development direction of our national culture. It promotes the development of our national culture in different kinds of ways and it is the basic elements of our national culture development.

Chinese characters greatly promote and influence the development of our national culture in each era. It is the important source and the basic guarantee for the development of our national culture.

\section{CHINESE CHARACTERS AND THEIR DESIGN}

In the process of continuous development of Chinese characters, different font evolution is a kind of font design process. They are innovated and consolidated while they are designed times and times by people.

\section{A. Chinese Characters Design in New Times}

Define abbreviations and acronyms, the first time they are used in the text, even after they have been defined in the abstract. Abbreviations such as IEEE, SI, MKS, CGS, sc, dc, and rms do not have to be defined. Do not use abbreviations in the title or heads unless they are unavoidable.

The era have entrusted to our new form. So we get the formal beauty of national characters changed at a deeper level. This change also comes from the need of economic development. A new era of Chinese characters should appear more font design to meet the needs of different areas.[3] Make the Chinese characters as information carrier of national culture more fully into all walks of life. This is the Chinese characters and Chinese character font design in an important relationship of commodity economy.

\section{B. The Important Role of Chinese Characters}

Chinese characters as the basic elements of Chinese characters font design play a major role. The development of diversification in the designer's thinking is used more widely. In today's rapid development in the information age, the designer should take advantage of existing Chinese characters as the basic design elements of different fonts. In different forms to create more Chinese characters font design work to meet the needs of the national culture of our enterprise. Such behavior can be compared into a bridge of economy and culture.

In understanding the development of the relationship between Chinese characters and national culture, we know the Chinese characters and Chinese character font design connect deeply. We have further understanding on the relationship between the Chinese character font design and the national culture. [4] So we should recognize the Chinese characters font design and the fusion of national culture is the key to solve the problem.

\section{THE FUSION OF CHINESE CHARACTERs Font DESIGN PERFORMANCE}

The integration of real Chinese character font design and the national culture refers to the important issues about the development and the application of the practical art design.

\section{A. The Fusion of Different Performance}

The design of the Chinese characters has different integration manifestations in different practical design fields. For example, in the field of Visual Communication Art Design, Chinese character form plays the important role due to its national characteristics. People promote the posters, book covers, corporate identity, packaging, materials, etc. by using Chinese characters form. The purpose of this can promote national cultural development better and faster. [5]Making all the art carriers of Chinese characters font design becomes more national. Because of the addition of the Chinese character elements, the art work can have the effect of promotion and popularization. Chinese character font design is applied most widely in the field of visual communication design. And it should become the designs' essential element.

The typeface design not only plays an important role in visual communication design. It also plays the national character concept in environmental art design, costume design, cartoon design, decoration art design, the digital media design. At the same time it can play an important role in promoting the national culture development in different ways.

\section{B. In the Field of Environmental Art Design}

In the field of environmental art design, the ancient Chinese architecture and interior design has the influence of characters. The Chinese character “门” can show the basic relationship between the Chinese hieroglyphs and environmental art. Many buildings measure the structure style 
of the building by Chinese characters typefaces. Chinese characters font design also reflected the adornment style with Chinese style in the interior decoration design.

\section{In the Field of Cartoon Design.}

In the field of cartoon design, the industry's technology and resources are limited, so it's necessary to add the Chinese character front design in to the cartoon design since it's in the developing stage. Publicity promotes the national cartoon industry. I think the typeface design element of intentionally imitate foreign work against the development of national card diffuse and animation. Considering the publicity of the national cartoon industry, it's not a good idea to imitate the foreign character designs, because it will make our design short of national characteristics.

\section{In the Field of Fashion Design}

In the field of fashion design, fashion has more and more prominent national features. Many Chinese characters font design can be seen in clothes. Many brand names and logos of the domestic clothing enterprises are on background of national culture. They have deeply realized that 'of the nation, of the world', which means that only it has a characteristic of nationality; it can survive in the world, which is the right development way of the enterprises.

\section{E. In the Field of Decoration Art Design}

In the field of decoration art design, Chinese character font design performance is more outstanding. In the decoration works, some traditional, modern, Chinese characters font design is an important and indispensable element. A design work without national characteristics [6] is uncompleted.

\section{F. In the Field of Graphic Design}

In the field of graphic design, the combination of fonts and graphics design has become a new trend. Under the trend of The Times of reading, a lot of Chinese characters font develop toward graphical design. Some graphic designers' work also show a strong sense of national culture, such as the famous Hong Kong designer Daiqiang Jin, his ink painting poster is the classic Chinese font culture in graphic design.

\section{G. In the Field of Digital Media Design}

In the field of digital media design, the main aspect is design of the film titles. The design characteristics about the combination of the dynamic performance and the image are fully embodied in the Chinese character front design. As a new carrier of art, the combination of the technology and the Chinese character effectively speeds up the integration between the Chinese character front design and the national culture.

\section{CONCLUSION}

To sum up, in the Chinese civilization history of five thousand years, the creation and development of the Chinese characters provides favorable conditions for the development of Chinese culture. Chinese character font design is very expressive. The integration between the Chinese character design and the national culture is the important factor for the development of the national culture. Consequently, more attention should be paid to the course about the Chinese character front design in the education of art design. As the designer, we should have a clear view about the trend of the future art design, the native national culture characteristics should be fully embodied in the art design. The national characteristics can't be lost under the influence of the foreign culture.

\section{REFERENCES}

[1] 'national culture'means national culture of China.

[2] Youguang Zhou, 'From the perspective of Chinese culture, there are macro and micro two aspects: macro, the characters as a cultural item, to explore its relationship with other cultural items; microcosmic, the Chinese characters as the carrier of culture, to explore the cultural information it conveys.' pp.79-81, Chinese characters and cultural issues, Liaoning people's publishing house, January 2000.

[3] Jiali $\mathrm{Wu}$, Chinese characters design,Tsinghua university press. Pp.81 November 2003. in press.

[4] Shouzhi Wang, 'Chinese character font design and the national culture'. The world history of graphic design , pp.351The China youth press, September 2002. published

[5] Jiaan Yang, An introduction to the art, Jilin art publishing house. In May 2003.

[6] Rudolph arne haim, Visual thinking The sichuan people's publishing house. In March 1998. 